\title{
Aktivitas Antifeedant dan Antioviposisi Ekstrak Daun Tithonia terhadap Kutu Kebul
}

\section{Antifeedant and Anti-oviposition Activities of Tithonia Leaf Extract to Giant Whitefly}

\author{
Dian Susanti ${ }^{1)}$, Rahma Widyastuti ${ }^{1}$, Ato Sulistyo ${ }^{2)}$
}

\section{ABSTRACT}

The increasing demand of jamu/traditional medicine was followed by the demands of raw materials quality based on Good Agricultural and Collection Practices (GACP) yield and standard quality. Bio-insecticide is an effort to fulfill the standard based on GACP. Indonesian's biodiversity have many potential raw materials of bioinsecticides, such as Tithonia diversifolia. The most common pest in the medicinal plants is Aleurodicus dugesii (giant whiteflies), this insect belong to Hemiptera ordo and Aleyrodidae family. The research was conducted to determine the antifeedant and anti-oviposition activity of Tithonia bio-insecticide against giant whitefly on Coleus species. The experimental design was completely randomized design (CRD) with five treatments of Tithonia leaves extract consentrations. Those consentrations were $0,4,2,1$, and $0,5 \mathrm{mg} \mathrm{L}^{-1}$. The treatments were tested by using a no-choice test with three replications. The extract of Tithonia leaves was prepared by infundation method by using water solvent. Results showed that extracts of Tithonia with the smallest concentration $(0,5 \mathrm{mg}$ $\mathrm{L}^{-1}$ ) has an active role as an anti-oviposition and antifeedant on giant whiteflies.

Keywords : Aleurodicus dugesii,T. diversifolia, botanical insecticide

\section{PENDAHULUAN}

Kebutuhan bahan baku jamu/obat tradisional mengalami peningkatan seiring tumbuhnya kesadaran masyarakat akan khasiat jamu. Hal ini memberi peluang besar bagi petani tanaman obat untuk meningkatkan hasil produksinya. Kebutuhan 31 jenis tanaman obat untuk bahan baku industri jamu, non jamu, bumbu serta untuk kebutuhan ekspor di Indonesia cukup tinggi, yakni dengan volume lebih dari 1000 ton/tahun (Pribadi 2009). Tingginya kebutuhan tersebut disertai dengan tuntutan keamanan dan kualitas mutu, sehingga budidaya tanaman obat harus memenuhi standar hasil dan kualitas yang sesuai dengan GACP (Good Agriculture and Collection Practice). Upaya pemenuhan standar tersebut dapat dilakukan dengan menggunakan pestisida atau insektisida nabati. Insektisida nabati merupakan alternatif pengembangan pengendalian hama dan penyakit yang murah, ramah lingkungan dan mudah didapatkan dengan cara memanfaatkan keanekaragaman flora yang melimpah (Oyedokun et al. 2011).

Indonesia memiliki kekayaan flora yang mengandung berbagai jenis tumbuhan yang berpotensi sebagai insektisida nabati. Banyaknya jenis tumbuhan yang memiliki khasiat sebagai insektisida nabati mendasari upaya penggalian potensi tumbuhan guna mencari alternatif pengendalian hama. Keunggulan insektisida nabati adalah murah dan mudah dibuat, relatif aman terhadap lingkungan, tidak menyebabkan keracunan

1) Researcher Staff of Deputy for Medicinal Plants and Traditional Medicine Tawangmangu, Karanganyar

2) Lecturer of Study Program of Agrotechnology, Faculty of Agriculture University of Sebelas Maret (UNS) in Surakarta.

Contact Author: dian.ssanti@gmail.com, ato.sulistyo021@gmail.com pada tanaman, sulit menimbulkan sifat kebal pada hama, kompatibel dengan cara pengendalian yang lain, menghasilkan produk pertanian yang sehat karena bebas residu insektisida kimia. Kelemahan insektisida nabati adalah: daya tahan yang singkat (sangat mudah berubah/terurai), perlu perencanaan volume aplikasi dengan cermat agar efisien, konsentrasi larutan yang dihasilkan masih tidak konsisten karena sangat tergantung pada tingkat kesegaran bahan baku. Tumbuhan yang berpotensi sebagai pestisida nabati di Indonesia lebih dari 40 jenis dari famili Meliaceae, Annonaceae, Asteraceae, Piperaceae dan Rutaceae, namun tidak menutup kemungkinan adanya famili lain yang berpotensi (Yusuf 2012).

Suryaningsih dan Hadisoeganda (2004), menyatakan bahwa petani Indonesia telah menggunakan insektisida nabati sejak tahun 1987. Tumbuhan yang banyak diaplikasi sebagai insektisida nabati antara lain ubi gadung (Dioscoea hispida), biji buah sirsak (Annona reticulate), kacang babi (Tephrosia spp.), mahoni (Swieteina macrophylla), mimba (Azadirachta indica), tembelekan (Tagetes erecta), Tithonia (Tithonia diversifolia) dan tembakau (Nicotiana tabacum).

Tithonia ( $T$ diversifolia) merupakan salah satu tanaman yang memiliki potensi untuk dimanfaatkan sebagai insektisida nabati karena ekstrak air dan ekstrak etanol tanaman Tithonia menunjukkan adanya toksisitas kontak (Oyedokun 2011). Ekstrak kasar daun Tithonia merupakan racun kontak bagi Atta cephalotes (Hymenoptera: Myrmicinae) (CastanoQuintana et al. 2013). Kandungan metabolit sekunder dari ekstrak minyak mentah Tithonia adalah sesquiterpen lakton, senyawa polifenol (flavonoid dan tannin) dan saponin (Bagnarello et al. 2009). Bunga, daun, batang dan akar Tithonia mengandung minyak atsiri. Hasil destilasi minyak atsiri menunjukkan bahwa masing-masing bagian tersebut mengandung $\alpha$ pinene $(60,9-75,7 \%)$, $\delta$-pinene $(7,2-11,0 \%)$ dan

Aktifitas Anteefedant dan Antioviposisi Ekstrak Daun Thitonia Terhadap Kutu Kebul

Dian Susanti, Rahma Widyastuti, Ati Sulistyo 
limonene (0,9-4,3\%) (Oladipupo et al. 2012). Telah banyak dilakukan penelitian mengenai khasiat tanaman Tithonia sebagai insektisida (Oyedokun et al. 2011, Adedire dan Akinneye 2004), anti-oviposisi (Aderire dan Akinneye 2004), larvasida (Bernard et al. 2012, Wardhana dan Diana 2014, Rusli et al. 2010), antifeedant (Ambosio et al. 2008), repellent (Valderrama-Eslava et al. 2009), dan nematisida (Odeyemi dan Adewale 2011).

Hama adalah binatang yang keberadaannya di ekosistem budidaya tanaman tidak dikehendaki karena menyebabkan kerusakan pada tanaman hingga menurunkan hasil produksi dan pada tingkat populasi tinggi dapat menyebabkan kematian tanaman hingga kegagalan panen (Untung 1996). Kutu kebul merupakan hama yang paling sering menyerang tanaman obat.

Kutu Kebul Aleurodicus dugesii atau biasa dikenal sebagai giant whitefly merupakan serangga dari ordo Hemiptera, famili Aleyrodidae. Kutu yang berasal dari Amerika Tengah ini menyebar hingga ke Indonesia pada tahun 2008. Kutu ini merupakan serangga yang bersifat polifagus dan lebih memilih tanaman dikotil berkayu sebagai inang termasuk tanaman kapas, tanaman buah dan tanaman hias (Muniappan 2011).

Kutu kebul menyerang tanaman pada fase nimfa dan imago. Serangan dilakukan dengan cara memasukkan mulut jarum mereka ke dalam jaringan vascular atau floem daun dan menghisap cairan tanaman. Kutu kebul mengeluarkan embun madu yang kemudian menumpuk di permukaan daun dan menjadi media pertumbuhan embun jelaga. Permukaan daun tanaman yang terserang embun jelaga menjadi berwarna hitam sehingga proses fotosintesis terhambat (Bellow et al. 2006, Tjahjadi 1989, Pracaya, 2005).

Perkembangbiakan kutu kebul cukup cepat pada wilayah dengan kondisi lingkungan yang sesuai. Faktor lingkungan yang mempercepat perkembangbiakan kutu kebul antara lain suhu tinggi dengan kelembaban rendah, waktu tanam yang tidak serempak, cuaca yang panas, dan aplikasi yang tidak tepat dosis (Marwoto dan Inayati 2011).

Tanaman inang yang digunakan dalam penelitian ini adalah tanaman Iler. Iler (Coleus artopurpureus) termasuk dalam famili Lamiaceae. Tanaman Iler memiliki khasiat sebagai penyembuh luka, anti nyeri, anti radang dan antioksidan (Tari et al. 2013).

Penelitian ini bertujuan untuk mengetahui aktivitas antifeedant dan anti-oviposisi insektisida nabati Tithonia pada kutu kebul.

\section{METODE PENELITIAN}

Penelitian dilaksanakan di Laboratorium Terpadu Balai Besar Penelitian dan Pengembangan Tanaman Obat dan Obat Tradisional (B2P2TO-OT) dan Rumah Uji Lapang di Lahan Pertanian di dekat B2P2TO-OT Tawangmangu pada bulan Mei - Desember 2014. Bahan yang digunakan dalam penelitian ini antara lain bibit tanaman ller (Coleus artopurpureus), daun tanaman Tithonia dan kutu kebul. Alat yang digunakan dalam penelitian ini adalah polybag, kotak rearing, kain strimin, sprayer, cangkul, blender dan rotavapor.

Penelitian merupakan jenis penelitian eksperimental dengan desain Rancangan Acak Lengkap (RAL) dan menggunakan 5 perlakuan konsentrasi ekstrak daun Tithonia yakni 4, 2, 1, 0,5 $\mathrm{mg} \mathrm{L}^{-1}$ dan kontrol, dengan 3 kali ulangan. Pengujian dilakukan dengan menggunakan populasi kutu kebul hasil rearing di rumah uji lapang. Masing - masing ulangan perlakuan diinfestasi dengan 10 ekor kutu kebul mengacu pada penelitian yang dilakukan oleh Afifah (Afifah et al. 2015).

\section{Pelaksanaan}

Rearing kutu kebul dilakukan dengan menggunakan tanaman ller ( $C$. artopurpureus) sebagai tanaman inang. Tanaman ller dan imago kutu kebul dimasukkan ke dalam kurungan pemeliharaan. Imago kutu kebul akan bertelur dan menetas menjadi nimfa. Nimfa berkembang menjadi imago setelah 7-10 hari (Solepale 2013). Selanjutnya imago tersebut diperbanyak kembali sampai diperoleh jumlah yang cukup. Imago dapat mencapai umur 2 bulan.

Pembuatan ekstrak Tithonia dan identifikasi kandungan kimia dilakukan dengan memisahkan bagian bunga, daun dan batang Tithonia. Bagianbagian tersebut dicuci dan dikeringanginkan, kemudian diekstraksi secara infundasi dengan pelarut air. Larutan hasil infundasi kemudian disaring menggunakan kertas saring. Larutan yang telah disaring diuapkan pelarutnya menggunakan rotavapor. Ekstrak kental masing-masing bahan diskrining fitokimia dengan beberapa uji penetesan dan juga dengan cara spot test yang dilanjutkan dengan penetapan sidik ragam kromatografi.

Pengujian antifeedant dilakukan dengan menggunakan tanaman inang yang dikurung satu persatu (menggunakan no choice test). Tanaman disemprot sesuai dengan perlakuan kemudian diinfestasi 10 ekor kutu kebul. Pengamatan yang dilakukan meliputi perilaku, mortalitas dan gejala fitotoksisitas akibat perlakuan. Gejala fitotoksisitas berupa daun bercak coklat, layu dan kematian jaringan. Pengamatan dilakukan selama 3 hari setelah aplikasi. Analisis data dilakukan dengan menggunakan One-Way ANOVA dengan taraf $5 \%$ dan apabila terdapat beda nyata dilanjutkan dengan uji DMRT 5\%.

Bagnarello et al. (2009), menggunakan metode ekstraksi maserasi dengan menggunakan pelarut $70 \%$ etanol dan menggunakan metode no-choice test untuk menentukan antifeedant dan anti-oviposisi dengan waktu pengamatan 48 jam.

\section{HASIL DAN PEMBAHASAN}

\section{Hinggapan Kutu Kebul}

Jumlah hinggapan kutu kebul yang disajikan pada Grafik 1 tidak menunjukkan adanya perbedaan pada hari pertama dan kedua, tetapi pada hari ketiga perlakuan dengan konsentrasi $0 \mathrm{mg}^{\mathrm{L}-1}$ (kontrol) lebih tinggi daripada perlakuan dengan konsentrasi $0,5,2$, dan $4 \mathrm{mg} \mathrm{L}^{-1}$. 
Hasil penelitian menunjukkan bahwa jumlah hinggapan kutu kebul pada daun yang diaplikasi berbagai konsentrasi ekstrak Tithonia lebih rendah dibanding daun yang tidak diberi insektisida nabati (kontrol). Perilaku tersebut menunjukkan bahwa kutu kebul menghindari daun yang telah diaplikasi ekstrak Tithonia karena adanya kandungan senyawa metabolit sekunder. Hal ini sesuai dengan penyataan Bagnarello et al. (2009), bahwa kriteria penentu aktivitas antifeedant adalah jumlah hinggapan kutu kebul dewasa pada bagian tanaman yang telah diaplikasi sesuai perlakuan. Metabolit sekunder yang terdapat dalam Tithonia berupa sesquiterpene laktone, senyawa polifenol berupa flavonoid dan tannin berperan sebagai antifeedant.

Aktivitas antifeedant ekstrak Tithonia terjadi karena adanya kandungan senyawa penghambat makan yang menutup atau mengacau sinyal-sinyal rangsangan makan yang terdapat pada makanan (Syahputra 2008). Ekstrak Tithonia dengan konsentrasi rendah $0,5 \mathrm{mg} \mathrm{L}^{-1}$ mampu memberikan hasil yang sama dengan penggunaan konsentrasi 4 $\mathrm{mgL}^{-1}$. Hal ini menunjukkan bahwa ekstrak Tithonia dapat digunakan sebagai insektisida nabati dalam usaha budidaya tanaman obat.

Selama pengamatan, tidak ditemui adanya jamur jelaga pada permukaan daun. Pertumbuhan jamur jelaga tidak terjadi karena jumlah embun madu yang dikeluarkan kutu kebul sangat rendah akibat aktivitas antifeedant insektisida nabati Tithonia. Selain itu, belum terlihat adanya semut pencari madu yang bersimbiosis dengan kutu kebul.

\section{Mortalitas Kutu Kebul}

Pengamatan mortalitas kutu kebul (Grafik 2) menunjukkan bahwa pada kematian tertinggi terdapat pada konsentrasi insektisida nabati Tithonia $4 \mathrm{mg} \mathrm{L}^{-1}$. Tingginya mortalitas disebabkan jumlah kandungan senyawa metabolit sekunder yang aktif berperan sebagai penghambat makan cukup tinggi. Senyawa ini secara langsung menghalangi kerja sel sensorik dan menyebabkan serangga mati kelaparan. Penggunaan metode no-choice test pada penelitian tidak memberi pilihan bagi kutu kebul untuk berpindah ke daun yang tidak diberi insektisida nabati Tithonia.

Antifeedant bekerja dengan cara merangsang syaraf penolak makan yang spesifik berupa reseptor kimia (chemoreceptor) yang terdapat pada bagian mulut (mouthpart). Reseptor kimia tersebut bekerja bersama reseptor kimia lainnya, dan menyebabkan gangguan persepsi rangsangan untuk makan (Mordue (Luntz) et al. 1998, Szentesi dan Bernays, 1984).

Kandungan senyawa Tithonia juga menghambat perkembangan tubuh serangga secara tidak langsung. Insektisida Tithonia menyebabkan serangga tidak dapat menjadi dewasa dan bereproduksi (Afifah et al. 2015). Senyawa metabolit sekunder dapat mengakibatkan gangguan pertumbuhan dan pergantian kulit, gangguan reproduksi, gangguan jaringan dan sel serangga. Cara kerja senyawa ini adalah mengganggu kerja sistem endokrin serta mengganggu hormon tubuh serangga (Mordue (Luntz) dan Nisbet 2000).

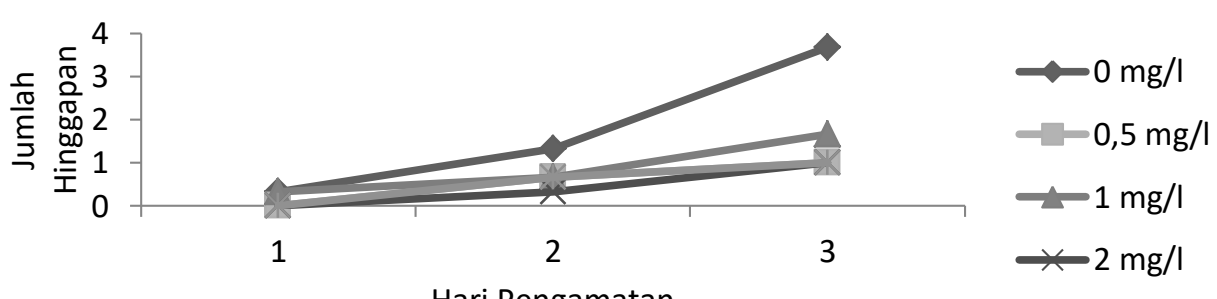

Hari Pengamatan

Gambar 1. Hinggapan kutu kebul (A.dugesii) pada pengujian antifeedant

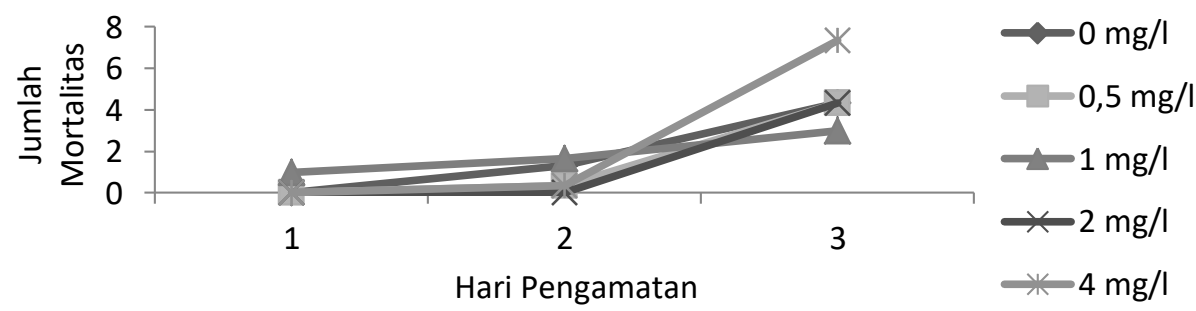

Gambar 2. Mortalitas kutu kebul pada pengujian antifeedant

\section{Persentase peletakan telur kutu kebul}

Peletakan telur (oviposisi) kutu kebul pada daun tanaman Iler yang diaplikasi konsentrasi ekstrak tanaman Tithonia lebih rendah dari daun tanaman Iler tanpa perlakuan ekstrak Tithonia (kontrol) (Tabel 1). Persentase oviposisi kutu kebul tertinggi terdapat pada konsentrasi $1 \mathrm{mg} / \mathrm{l}$ sebesar $31,67 \%$ dan terendah pada konsentrasi $0,5 \mathrm{mg} \mathrm{L}^{-1}$ sebesar $16,67 \%$. Perbedaan besar persentase oviposisi menunjukkan bahwa selain aktivitas antifeedant, ekstrak tanaman Tithonia juga memiliki aktivitas antioviposisi (penghambat peletakan telur). Anti-oviposisi merupakan aktivitas dimana senyawa metabolit sekunder berupa flavonoid yang terkandung dalam tanaman bersifat menolak atau menutupi sinyal penarik yang terdapat dalam tanaman inang (Bernays dan Chapman 1994). 
Aktivitas anti-oviposisi kutu kebul memiliki korelasi dengan aktivitas penolak makan terhadap tanaman inang dan rangsangan makanan yang ditimbulkan oleh tanaman inang. Menurut Hosang et al. (2005), serangga berinteraksi dengan tanaman inang untuk tujuan peletakan telur, mendapatkan makanan dan tempat berlindung dengan adanya pengaruh kandungan senyawa sekunder tanaman tersebut.

Tabel 1. Persentase peletakan telur kutu kebul

\begin{tabular}{ll}
\hline Konsentrasi $\left(\mathrm{mg} \mathrm{L}^{-1}\right)$ & Peletakan telur kutu kebul selama 3 hari (\%) \\
\hline 0,0 & $82,22 \mathrm{a}$ \\
0,5 & $16,67 \mathrm{~b}$ \\
1,0 & $31,67 \mathrm{~b}$ \\
2,0 & $25,00 \mathrm{~b}$ \\
4,0 & $21,67 \mathrm{~b}$
\end{tabular}

Angka-angka pada lajur yang sama diikuti oleh huruf kecil yang sama berbeda tidak nyata menurut DMRT pada taraf nyata $5 \%$.

\section{Gejala fitotoksik ekstrak tanaman Tithonia}

Hasil pengamatan selama 3 hari setelah aplikasi menunjukkan bahwa beberapa konsentrasi ekstrak Tithonia yang digunakan tidak menimbulkan gejala fitotoksik, baik berupa bintik atau bercak coklat, layu atau kematian jaringan daun. Hal ini menunjukkan bahwa penggunaan ekstrak Tithonia sebagai insektisida nabati dengan konsentrasi yang tepat tidak berefek negatif terhadap tanaman inang. Penggunaan konsentrasi yang terlalu tinggi akan menyebabkan terhambatnya pertumbuhan tanaman (llori et al. 2007).

\section{Uji Fitokimia}

Hasil uji fitokimia (Tabel 2) menunjukkan bahwa tanaman Tithonia mengandung komponen senyawa metabolit sekunder berupa alkaloid dan flavonoid.

Otusanya and llori (2012), menyatakan bahwa hasil skrining fitokimia dengan pelarut methanol dan air ekstrak Tithonia mengandung flavonoid, tannin, glikosida, terpenoid dan fenol. Pengujian lebih lanjut dengan pelarut methanol menunjukkan bahwa ekstrak Tithonia mengandung saponin dan alkaloid.

Tabel 2. Hasil pengujian fitokimia ekstrak tanaman Tithonia.

\begin{tabular}{lllll}
\hline \multirow{2}{*}{$\begin{array}{l}\text { Bagian } \\
\text { tanaman }\end{array}$} & \multicolumn{3}{c}{ Skrining fitokimia } & \multicolumn{2}{c}{ KLT } \\
\cline { 2 - 5 } & Alkaloid & Flavonoid & Alkaloid & Flavonoid \\
\hline Daun & + & - & + & + \\
Batang & + & - & + & + \\
Bunga & + & - & + & + \\
\hline
\end{tabular}

Keterangan: ( + ) Ada, ( - ) Tidak ada.

\section{KESIMPULAN DAN SARAN}

\section{Kesimpulan}

Berdasarkan hasil penelitian, dapat diambil kesimpulan bahwa ekstrak tanaman Tithonia dengan konsentrasi terkecil $0,5 \mathrm{mgL}^{-1}$ pada tanaman Iler sudah aktif berperan sebagai antifeedant dan antioviposisi kutu kebul. Selain itu ekstrak tanaman Tithonia dengan konsentrasi tertinggi $\left(4 \mathrm{mgL}^{-1}\right)$ masih cukup aman untuk digunakan sebagai insektisida nabati karena tidak bersifat fitotoksik terhadap tanaman yang diaplikasi.

\section{Saran}

Perlu dilakukan penelitian lebih lanjut terhadap senyawa aktif yang bermanfaat sebagai antifeedant ataupun sebagai anti-oviposisi, terutama senyawa sesquiterpene laktone.

\section{PERSANTUNAN}

Penulis mengucapkan terima kasih kepada Kepala Badan Litbang Kesehatan yang telah memberikan dukungan secara finansial dan lbu Indah Yuning Prapti, SKM, M.Kes selaku Kepala Balai Besar Litbang Tanaman Obat dan Obat Tradisonal yang memberikan ijin menggunakan fasilitas dalam pelaksanaan penelitian ini. Penulis juga mengucapkan terimakasih kepada lbu Retno Wijayanti yang telah membantu pelaksanaan penelitian ini.

\section{DAFTAR PUSTAKA}

Adedire CO, Akinneye JO. 2004. Biological activity of tree marigold, Tithonia diversifolia, on cowpea seed bruchid, Callosobruchus maculates (Coleoptera: Bruchidae). Ann Appl Biol 144: 185189.

Afifah F, Rahayu YS, Faizah U. 2015. Efektivitas kombinasi filtrat daun tembakau (Nicotiana tabacum) dan filtrat daun paitan (Thitonia diversifolia) sebagai pestisida nabati hama walang sangit (Leptocorisa oratorius) pada tanaman padi. LenteraBio 4 (1): 25-31. 
AmbosioSR, Oki Y, Heleno VCG, Chaves JS, Nascimento PGBD, Lichston JE, M. G. Constantino MG, Varanda EM, Da Costa FB. 2008. Constituents of glandular trichomes of Tithonia diversifolia: Relationshios to Herbivory and Antifeedant activity. Phytochemistry 69: 20522060.

Bagnarello G, Hilje L, Bagnarello V, Cartin V, Calvo M. 2009. Actividad fagodisuasiva de las plantas Tithonia diversifolia y Montanoa hibiscifolia (Asteraceae) sob re adult os del insectoplaga Bemisia tabaci (Homoptera: Aleyrodidae). J Revista de Biol Trop. 57(4): 1201-1215.

Bellow TS, Kabashima JN, Robb KL. 2006. Giant whitefly integrated pest management for home gardeners and landscape professionals. Pest Notes UCANR Publication 7400. www.ipm.ucdavis.edu/PMG/.../pn7400.html.

Diakses 15 Desember 2104.

Bernard LK, David SK, Mark NO, Charles MK, Geoffrey RM, Charles M, Laban I, Willy TK. 2012. Larvicidal Action of extracts from Tithonia diversifolia Against the Dengue Mosquito Aedes aegypti (Diptera: Culicidae), J Biol Act Prod Nat 2(1): 46-49, DOI: 10.1080/22311866.2012.10719107.

Bernays EA, Chapman RF. 1994. Host-plant selection by phytophagus insects. contemporary topics in entomology 2. New York (NY): Chapman and Hall.

Castano-Quintana K, Mantoya-Lerma J, GiraldoEcheverri C. 2013. Toxicity of foliage extracts of Tithonia diversifolia (Asteraceae) on Atta cephalotes (Hymenoptera: Myrmicinae) workers. Indust Crop Prod. 44: 391-395.

Hosang MLA, Alouw JC, Sabbatoellah S. 2005. Interaksi antara hama Sexava spp. dengan tanaman inang. Monograf Hama dan Penyakit Kelapa: 27-34.

Ilori OJ, Otusanya OO, Adelusi AA. 2007. Phytotoxic Effects of Tithonia diversifolia on Germination and Growth of Oryza sativa. Research Journal of Botany 2(1): 23-32.

Marwoto, Inayati A. 2011. Kutu kebul: hama kedelai yang pengendaliannya kurang mendapat perhatian. Iptek Tanaman Pangan 6(1): 87-98.

Mordue (Luntz), A. J., M. S. J. Simmonds, S. V. Ley, W. M. Blaney, W. Mordue, M. Nasiruddin and A. J. Nisbet. 1998. Actions of Azadirachtin, a Plant Allelochemidal, against Insect. Pestic. Sci. 54: 277284.

Mordue (Luntz) A. J. and A. J. Nisbet. 2000. Azadirachtin from the Neem Tree Azadirachta indica: its Action Against Insects. An. Soc. Entomol. Brasil 29:615-632.

Muniappan, R. 2011. Recent invasive Hemipterans and their biological control in Asia.

(https://www.icac.org/tis/regional_networks/asian_ network/meeting_5/documents/papers/PapMuniap panR.pdf, diakses 16 Desember 2014.
Oladipupo, A.L., Adeleke A.K., Andy R.O. and Adebola O.O. 2012. Volatile constituents of the flower, leaves, stems and roots of Tithonia diversifolia (Hemsely) A. Gray. Journal of Essential Oil Bearing Plants. 15(5): 816-821.

Otusanya, O. and O. Ilori. 2012. Phytochemical screening and the phytotoxic effects of aqueous extracts of Tithonia diversifolia (Hemsl) A. Gray. International Journal of Biology 4(3): 97-101.

Oyedokun AV, JC. Anikhe, F.A. Okelana, I.U. Mokwonye and O.M. Azeez. 2011. Pesticidal efficacy of three tropical herbal plants' leaf extracts against Macrotermes bellicosus an emerging pest of cocoa, Theobroma cacao L. Journal of Biopesticides 4(2): 131-137.

Odeyemi IS, Adewale KA. 2011. Phythonematoxic properties and nematicidal potential of Tithonia diversifolia extract and residue on Meloydogyne incognita infecting yam (Discoria rotundata). Arch Phytopathol Plant Protect 44(18): 1745-1753. DOI:10.1080/03235400903461039.

Pracaya. 2005. Hama dan penyakit tanaman. Jakarta (ID): Penebar Swadaya. 417 hal.

Pribadi, ER 2009. Pasokan dan permintaan tanaman obat Indonesia serta arah penelitian dan pengembangannya. Perspektif 8(1): 52-64.

Rusli, R., Arneti, dan SP Sari. 2010. Pengujian ekstrak metanol bunga kipat (Tithonia Diversifolia A. Gray) (Asteraceae) untuk mengendalikan Spodoptera Exigua Hubner (Lepidoptera: Noctuidae). Manggaro 11(1):25-32.

Solopale, S. 2013. Kutu daun (Myzus persicae). www.pengenalanhama.blogspot.com/2013/08/kutu -daun-myzus-persicae.html. Diakses tanggal 8 Januari 2014.

Suryaningsih, E. dan W. W. Hadisoeganda. 2004. Pestisida botani untuk mengendalikan hama dan penyakit pada tanaman sayuran. Monografi No. 26. Balai Penelitian Tanaman Sayuran. Balitbangtan. Jakarta.

Syahputra E. 2008. Bioaktivitas sediaan buah Brucea javanica sebagai insektisida nabati untuk serangga hama pertanian. Bul. Littro. XIX(1): 57-67.

Szentesi A, Bernays EA. 1984. A Study of behavioural habituation to a feeding deterrent in nymph of Schistocerca gregaria. Physiological Entomology 9: 329-340.

Tari R, Posangi J, Wowor PM. 2013. Uji efek daun iler (Coleus Atropurpureus [L.] Benth.) terhadap penyembuhan luka insisi pada kulit kelinci (Oryctolagus Cuniculus). Jurnal E-Biomedik (Ebm) 1(1): 581-586.

Tjahjadi N. 1989. Hama dan penyakit tanaman. Yogyakarta (ID): Kanisius.

Valderrama-Eslava El, Montoya-Lerma J, Giraldo C. 2009. Enforced Herbivory on Canavalia ensiformis and Tithonia diversifolia and its Effects on LeafCutting Ants, Atta cephalotes. J Appl Entomol. 133: 689-694. 
Wardhana AH, Diana N. 2014. Aktivitas biolarvasidal ekstrak metanol daun kipahit (Tithonia diversifolia) terhadap larva lalat Chrysomya bezziana. JITV 19(1): 43-51.

Yusuf R. 2012. Potensi Dan Kendala Pemanfaatan Pestisida Nabati dalam Pendalian Hama Pada Budidaya Sayuran Organik. Makalah Dalam
Seminar Ur-Ukm Ke-7: Optimalisasi Riset Sains dan Teknologi Dalam Pembangunan Berkelanjutan.

Untung K. 1996. Pengantar pengelolaan hama terpadu. Yogyakarta (ID): Gadjah Mada University Press. 